\title{
Multiple Researcher Roles in Video-Reflexive Ethnography
}

Citation for published version (APA):

Carroll, K., \& Mesman, J. (2018). Multiple Researcher Roles in Video-Reflexive Ethnography. Qualitative Health Research, 28(7), 1145-1156. https://doi.org/10.1177/1049732318759490

Document status and date:

Published: 01/06/2018

DOI:

$10.1177 / 1049732318759490$

Document Version:

Publisher's PDF, also known as Version of record

Document license:

Taverne

Please check the document version of this publication:

- A submitted manuscript is the version of the article upon submission and before peer-review. There can be important differences between the submitted version and the official published version of record.

People interested in the research are advised to contact the author for the final version of the publication, or visit the DOI to the publisher's website.

- The final author version and the galley proof are versions of the publication after peer review.

- The final published version features the final layout of the paper including the volume, issue and page numbers.

Link to publication

\footnotetext{
General rights rights.

- You may freely distribute the URL identifying the publication in the public portal. please follow below link for the End User Agreement:

www.umlib.nl/taverne-license

Take down policy

If you believe that this document breaches copyright please contact us at:

repository@maastrichtuniversity.nl

providing details and we will investigate your claim.
}

Copyright and moral rights for the publications made accessible in the public portal are retained by the authors and/or other copyright owners and it is a condition of accessing publications that users recognise and abide by the legal requirements associated with these

- Users may download and print one copy of any publication from the public portal for the purpose of private study or research.

- You may not further distribute the material or use it for any profit-making activity or commercial gain

If the publication is distributed under the terms of Article $25 \mathrm{fa}$ of the Dutch Copyright Act, indicated by the "Taverne" license above, 


\title{
Multiple Researcher Roles in Video-Reflexive Ethnography
}

Qualitative Health Research 2018, Vol. 28(7) II45-II56 (C) The Author(s) 2018 Reprints and permissions: sagepub.com/journalsPermissions.nav DOI: I0.II77//0497323/8759490 journals.sagepub.com/home/ghr (SSAGE

\author{
Katherine Carroll' and Jessica Mesman ${ }^{2}$
}

\begin{abstract}
Hospital-based video-reflexive ethnography (VRE) is a collaborative visual methodology used by researchers and/ or health professionals to understand, interpret, and optimize health professionals' work practices and patients' experiences. For more than a decade, the VRE methodology has spread throughout (research) institutions and hospitals internationally, and VRE has evolved and broadened. Different ways of doing VRE have implications for the role of the researcher. A thorough examination of the consequences for the researcher's position is the central focus of this article. We outline three typical styles of researcher engagement with VRE: clinalyst, affect-as-method, and planned obsolescence. We argue that by examining these different styles of doing VRE research, academic researchers can then critically review and carefully choose which styles of VRE research best meet the needs of their research questions, their field relationships, their disciplinary background, and the expectations of their clinical research collaborators.
\end{abstract}

\section{Keywords}

reflexivity; hospitals; research design; methodology; epistemology; ethnography; Australia; United States of America; Europe; United Kingdom

\section{Introduction}

Video-reflexive ethnography (VRE) is a collaborative visual methodology used by researchers and/or participants such as health professionals or patients to understand, interpret, and optimize "everyday" work practices enacted by teams in a naturalistic setting (Iedema, Mesman, \& Carroll, 2013). The VRE methodology centers on recording day-to-day work and then showing back select video footage for interpretation and discussion with participants in "video-reflexive sessions." The video-reflexive sessions provide moments of further data collection in addition to new directions and practical suggestions for practice improvement (Iedema et al., 2013). As such VRE encompasses two different, but highly interrelated aims: academic research and practice optimization. The twin goals have important implications for VRE researchers, as their work will now be judged for admissibility to peer-reviewed publications and for its worthiness as an intervention tool and source of reflection for quality improvement in professional practices. These twin aims are important to consider for methodological reasons, but in addition to this, they are important to attend to because of the consequences for both knowledge production and intervention. To understand these methodological implications, one requires an indepth understanding of VRE, and what the three modes of doing VRE offer. This preparatory groundwork is needed to understand our argument that it is of critical importance that the VRE researchers' contribution to knowledge production and intervention in practice are attended to in research design and reporting.

In this article, we focus on hospital-based VRE. However, this does not imply that this methodology is limited to hospital practices. Forms of VRE are also used in control-rooms in the railroad sector, in educational settings, in the military, and with elite sports teams. Our focus on health care is motivated by our own experiences in this area (Iedema et al., 2013), by the increasing popularity of VRE in diverse clinical domains, ${ }^{1}$ and by it being considered as a critical resource for health professionals themselves to focus on, and redesign localized technical, interpersonal, and affective dimensions of health care practices (Iedema, Long, Forsyth, \& Lee, 2006).

Originating in Australia, the VRE methodology has not only evolved and broadened but has spread throughout

\footnotetext{
'The Australian National University, Canberra, Australian Capital Territory, Australia

${ }^{2}$ Maastricht University, Maastricht, The Netherlands

Corresponding Author:

Katherine Carroll, Research Fellow, School of Sociology, College of Arts and Social Sciences, The Australian National University, Haydon-Allen Building \#22, Acton, Australian Capital Territory 260I, Australia.

Email: Katherine.Carroll@anu.edu.au
} 
hospitals in the United Kingdom, Europe, and North America. During the first decade of its deployment, VRE typically involved collaborative research agenda setting with health professionals, with the researcher maintaining control of the camera during data collection (Carroll, 2009; Carroll \& Mesman, 2011; Iedema \& Carroll, 2010, $2011,2013)$ and chairing the video-reflexive sessions with health professionals who are involved in the bulk of discussion and interpretation of video footage.

Today, after more than a decade of evolution, the VRE methodology has diversified, and so too has the role of the VRE researcher. For example, health professionals or patients may now direct the videoing of hospital practices, in addition to identifying topics for analysis in video-reflexive sessions as a means to access deeper meanings about patient experiences and participation in care (Collier, 2013; McLeod, 2017; Wyer et al., 2015). In addition, the VRE methodology has also evolved to bolster the affective expertise of the patient, health professional, or researcher, who are inspired through interactions to co-intervene in, or advocate for certain aspects of practice in hospital life (Iedema \& Carroll, 2015). Regardless of the kind of participants (health professionals or patients), the diversification of VRE has implications for the role of the academic researcher. It is this changing role of the VRE researcher and its implications for knowledge production and practice optimization in particular that is the focal point of our analysis.

To analyze the mediating role of the researcher, this article discusses the three typical modes of "doing" VRE. These three styles should not be considered as pure typologies as they share many foundations of collaborative ethnographic research design and interventionist goals. The slippage between each mode of doing VRE acknowledges that in practice, there is fluidity in the application of the methodology, which we see as strength for adapting to the demands of local research contexts. Yet, in each mode, we highlight the diverse ways that researchers may position themselves, and, as a consequence, form different relationships in the field and produce different texts in academic knowledge production (Carter \& Little, 2007; Harrison, 2002).

In the next section, we offer an overview of the VRE methodology and the reflexive and interventionist demands VRE places on researchers and participants. In doing so, we situate VRE among other research methodologies and explain its predominate site of use: hospitals. Following this, we describe the three roles that the VRE researcher may typically adopt (which we will call the clinalyst, affect-as-method, and planned obsolescence), and the associated consequences for knowledge production and practice intervention. In doing so, we draw on and describe our long-standing experience of using VRE in each of these roles (Iedema et al., 2013). We argue that each role of the researcher in VRE comes with a different set of epistemic and interventionist concerns which have implications for the way one pursues the twin goals of VRE: research and practice optimization.

\section{VRE: Phases, Field Sites, and Methodological Position}

Once field site access and human ethics research approval have been granted, VRE can be best described as consisting of three distinct but interrelated phases in terms of how it is deployed in various hospitals. These are video ethnography, video-reflexivity, and practice optimization/academic publication, and are important to understand before detailing how the researcher's role in each of the three modes of doing VRE may shape each of its distinct phases.

\section{Video Ethnography}

In the first phase of VRE, data are collected through ethnographic and video ethnographic means. This may involve observations, field interviews, and document analysis in addition to videoing in situ work practices of health care professionals, patients, or their families. VRE involves concurrent data collection and analysis, during which a team of health professionals and/or patients, the researcher, and other key stakeholders will decide upon a focused topic of interest to them for further analysis in video-reflexivity sessions. This decision shapes where ethnographic videoing will occur in the hospital, for example, in which unit, with which professional roles, or with regard to which particular work practices. The videoing of these situations may vary in style depending on how the camera is used and how participants choose to engage with the camera and its operator. These styles have implications for both the production of knowledge and the relationship with the health care professionals (Carroll, 2009; Forsyth, 2009; McLeod, 2017).

\section{Video-Reflexivity}

During video-reflexivity sessions, video footage is shown back to the participants in researcher-facilitated sessions. The video footage acts as a prompt for health professionals or patients to discuss daily health care practices in a nonpunitive way. To prepare for these reflexive viewings, a selection of footage is made, most often by the researcher. This selection is based on several criteria such as level of work practice detail depicted, clear visibility or audio, routine or exceptional case selection, and diversity of task execution, to name a few. This footage is then edited on the basis of its usefulness for the topic of focus in the reflexivity session, 
resulting in the selection of several short clips. The selected video clips are then shown back to participants for analysis, and the reflexive sessions themselves are also videoed. It is advantageous to video record (in the same frame) participant interactions, the researcher, and also the screen which displays the footage. This will enable analysis of the moments of realization and transformation arising from the reflexive session, and provide an account of the research process itself (Harrison, 2002; Kindon, 2003). The reflexive sessions offer a platform to turn participants into co-researchers by blurring the boundary between the analyst and the participant, and between knowledge generation for the purpose of academic research and practice optimization. The data constructed during these discussions can act as vital input for the academic argument of the researcher, while at the same time is a compilation of the evaluated suggestions for improvement and a point of departure for health professional-led practice optimization.

\section{Practice Optimization and Academic Publication}

The third phase of the VRE methodology involves building an academic argument for publication and/or health professional-led practice optimization. Practice optimization may take the form of the implementation of any changes to practice as a result of collectively viewing and discussing footage during video-reflexivity. Or, it may take the form of team learning. Participation in video-reflexivity sessions requires particular skills of health professionals, such as collective attention and passivity competence. Collaborative attention is the capacity of "having the patience to be open-open to what colleagues are doing and saying, open to the implications of what they are doing and saying, and open to colleagues having questions about what is appropriate to do and say" (Iedema et al., 2013, p. 14). Collaborative attention requires passivity competence, ${ }^{2}$ which is the capacity for paying attention to events without immediate reaction to them. This delayed response enables the health care professionals "to become sensitized to a greater array of impressions" (p. xvii), which expands their capacity for effective action in optimizing their future practices. The academic researcher, on the contrary, obtains further insight from video-reflexivity, including clarification, confirmation, and contestation resulting from standing alongside health professionals as their own analytical frame is exposed to participants in conjunction with the analytic word of the health professionals (Carroll, 2009). The video recording of the reflexive session forms a third data set in addition to the ethnographic and video ethnographic data that can contribute further to academic publication.

\section{Positioning VRE in Research Traditions}

Before providing more detail on the different researcher roles involved in the three modes of doing VRE, it is important that we first position the VRE methodology in relation to existing research methodologies and visual methods. VRE, as its name suggests, stems from an ethnography, which aims to provide a deeper, more informed account of the participants and their everyday life on the basis of long-term observations and interactions (Willis, 2010). In classic ethnography, researchers use a camera fundamentally to collect data. Ethnographic film, on the contrary, is a polished end product of community-collaborative and ethnographic filmmaking that communicates anthropological knowledge (Ruby, 2005). ${ }^{3}$ However, in VRE, the aim of the footage produced is to generate conversation among local participants about their practice rather than solely to collect data or to produce a polished film for dissemination to wider audiences. Moreover, VRE is reliant upon the "video-reflexivity" session where participants are requested to reflect on the footage. Thus, it is the reflexive component that involves participants for the purpose of practice optimization and team learning, and which causes VRE to be distinct from "video ethnography" and ethnographic film.

VRE is also distinct from other methods that involve the use of video, such as visual anthropology (Adomat \& Hicks, 2003; Pink, 2013; Xiao \& Mackenzie, 2004; Xiao, Seagull, Mackenzie, \& Klein, 2004), simulation (Siassakos et al., 2011), audits (Williams, Jones, Richardson, Jones, \& Richmond, 1996), and educational sessions (Guerlain, Turrentine, Adams, \& Calland, 2004; Heath, Luff, \& Svensson, 2007; Lammer, 2009). These methods necessarily include video-reflexivity as a component of the method, but not necessarily the contemporaneous achievements of practice optimization and research. Besides practice improvement and academic research, VRE is also characterized by its collaborative nature. It shares this with other approaches, like "participatory cinema" which also collaborates closely with participants. The camera is used as an ethnographic tool where participants are invited to reflect on the footage and comment on the way the visual footage reflects their everyday life. These discussions are considered as ethnographic opportunities for knowledge production, a form of "shared anthropology" (Jørgensen, 2007) and potential for empowerment and agency (Pink, 2001). However, a chief distinction between participatory cinema and VRE is VRE is intended to improve (not merely describe) the practices enacted by health professionals. As such, the aim of VRE is united with the aims of applied and public visual anthropology and applied sociology to, in addition to producing scholarly research, make social interventions outside of academia (Pink, 2011). ${ }^{4}$ Thus, VRE is a 
collaborative methodology constituted by two interrelated components - "video ethnography" and "videoreflexivity," which collectively intervene in, and produce practice change in health care.

\section{Three Researcher Roles of Doing VRE: Clinalyst, Affect-as-Method, and Planned Obsolescence}

VRE has been variously implemented in many hospitals around the world. Included in this variation is the role of the academic VRE researcher. The researcher's approach can be quite different at different hospital sites, and as a result of different field relationships, research questions, and varying access to the field. It is important to ask, therefore, what does VRE become through each style of engagement? What are the implications, for example, for the organization of the work that is needed to deploy the VRE methodology? Moreover, what are the implications for the knowledge produced through each style of engagement? It is important for academic VRE researchers to critically review these questions and to understand, and choose which styles of VRE research best meet the needs of their research questions, field relationships, and disciplinary background. We will now discuss three styles of researcher engagement: the clinalyst, affect-as-method, and planned obsolescence.

\section{The Clinalyst: Catalyzing Insider's Knowledge}

The majority of the VRE literature published to date characterizes the role of the researcher as an analyst of health professionals' practices in the hospital ${ }^{5}$ (Iedema \& Carroll, 2011; Iedema et al., 2006; Iedema et al., 2009; Iedema et al., 2013). The "clinalyst," a notion coined by Iedema and Carroll (2011), is shorthand for "outsideranalyst-catalyst" (p. 176). Through the use of VRE, the clinalyst acts as an ethnographer and a catalyst for health professional-led practice change. A clinalyst utilizes knowledge that spans the health sciences and organizational or social sciences, and is comfortable as a change agent through facilitating video-reflexive sessions during which health professionals articulate and negotiate the complexities specific to their health care delivery (Iedema \& Carroll, 2011). By using these competencies, the clinalyst catalyzes insiders' knowledge by asking outsider questions while collaboratively viewing video footage with health professionals. For both the researcher and the health professionals, the reflexivity sessions are a crucial moment for gaining insights into work processes and are one of the few places where day-to-day matters are explicitly articulated and discussed.

Although the clinalyst leads the project, health care professionals are important partners in the process of knowledge production. The specification of the topic to be videoed, although related to the research project of researcher, is also collaboratively defined in advance with local stakeholders. For example, a research project may have an overall focus on patient safety. After consultation with stakeholders, it may target infection prevention. Then, following initial fieldwork, the topic might then be specified further to focus on catheter-related bloodstream infections. This collaborative and emergent engagement with local stakeholders reveals the shared decision making about what to video regarding patient safety and infection prevention. Thus, health care professionals are crucial to the success of this collaborative approach. Besides their involvement in the selection of topics and videoing, they also play a role in the preparation of the reflexive sessions. Before reflexivity sessions, the edited clips are first reviewed by those featured in footage to ensure consent is given, and the specific time and place for the reflexivity sessions are decided in negotiation with the participants.

Whereas improving the health care practice is a shared objective by the clinalyst and the health care professionals, the objective for the health professionals is to learn from each other with the help of VRE and, if needed, adjust their ways of working. For this reason, their focus is on the content of the footage and the practical implications of their discussion. The objective of the researcher, however, is to create a passage point to the "inside knowledge" (Mesman, 2015; Pinch, Collins, \& Carbone, 1996), allowing him or her to follow practical matters to gain in-depth insight into the diversity of meanings and experiences of these issues in practice. The clinalyst, therefore, has a large degree of control. The knowledge that is co-produced by the clinalyst and the health care professionals largely stays in the hands of the clinalyst, and the clinalyst facilitates the reflexive sessions. Yet this control, we will later discuss, may not always be advantageous as it is reliant upon the motivation and acceptance of VRE by the health care professionals.

\section{Affect-as-Method: A VRE Driven by Affect}

Doing VRE means significantly investing in forming relationships, building trust, and expending efforts to collaboratively become "entangled" with professionals and the field site itself (Carroll, Iedema, \& Kerridge, 2008). Affective sensitivity, researcher reflexivity, and vulnerability are competencies crucial to doing participatory and interventionist video research (Bloustein, 2003; Carroll, 2009). Yet, they are noticeably absent from the skills attributed to the clinalyst researcher. Iedema and Carroll (2011) cast the clinalyst as one who is aware of the affective dimensions of the clinical team being researched but personally not involved: "The clinalyst occupies this 
organizational-moral-reflexive space, being attuned to but not implicated in the normative-affective fabric of the clinical unit" (p. 186, emphasis added). Similarly, in their later work, Iedema et al. (2013) overlook the affective belonging and influence of the researcher. In this later account, the flow of affect is cast as part of the clinical team's intelligence and, through the use of VRE it, "highlights and reveals relationships in their affective aspect" (p. 38).

In this article, affect is defined as not only emotion but also precognitive bodily knowing-then-acting (Thrift, 2004). Acting on and through the subject, affect offers an "immanent potential that inheres in any present, rendering it complex, transformable and open to the unpredictability of the future" (Hynes \& Sharpe, 2015, p. 118). Although individuals are subject to the felt qualities of affect, affect is not the property of a subject; instead, he or she is "subject to its intensities and vicissitudes" (Hynes \& Sharpe, 2015, p. 118) of potential, which adds "intensity to action and events" (Hynes, 2013, p. 561). This shared intercorporeal affective flow is afforded to the use of participatory video methods (Bloustein, 2003), including VRE itself (Iedema et al., 2013). However, as affect has been currently applied to the VRE methodology, it often overlooks the inclusion of the researcher. For example, in the clinalyst role, affective knowing is attributed to clinical team members, yet stops short of being attributed also to the researcher. Without wanting to crudely instrumentalize affect (Hynes \& Sharpe, 2015), this oversight means that there is little room to acknowledge, analyze, and capitalize on the important affective momentum that the researcher herself participates in, generates, and is affected by, as a result of being included in the clinical team and in successfully doing VRE research. Herein lays the primary addition of the affect-as-method mode of doing VRE: There is potential for the researcher to explore, theorize, and acknowledge participation in the accrual of affective potential which, in turn, can be directed toward interpreting and intervening in the field site. Three more recently published works on VRE involving patients exemplify this.

In their most recent work, Iedema and Carroll (2015) apply affect theory to the VRE researcher's "ethics of practice" (p. 67). In their study of donor breast milk policy in neonatal intensive care, they outline how the VRE researcher becomes unexpectedly "embroiled" in the specific issue of equity in health care, and then embarks upon a particular course of interventionist action using VRE. Importantly, the distinguishing feature of affect-as-method in VRE is the affective enrollment of the researcher. Like other's positioning of affect in methodology (e.g., Clough, 2009), Iedema and Carroll (2015) do not prescribe a way of "doing affect" in this mode of VRE research, which has subsequently been labeled as "postqualitative" (Wyer et al., 2017). Unlike instrumentalized methodological orderliness, such prescription is removed from researcher engagement (Cheshire, 2016; Law, 2005; Wyer et al., 2017): "VRE defers conventional role allocations, using neither precircumscribed data set or strictly proceduralised analytical methods and taking local complexity and future action as points of departure" (Wyer et al., 2017, p. 8). Doing VRE through affect-as-method is therefore highly uncertain for the researcher; it is a position that is subject to the dynamics of the relationships in the field in conjunction with the researcher's inherent vulnerability arising from being present and accountable during videoreflexive sessions (Carroll, 2009). It is the researcher's style of being present through "being together" that ensures that the researcher is part of the affective flow that shapes not only the "nature and quality of the footage produced" through video-reflexive research but also the impetus to act as a result of the engagement (Iedema \& Carroll, 2015, p. 71). Thus, like their earlier conceptualization of the "clinalyst" mode of doing VRE, here Iedema and Carroll return to the importance of embedded relationships in the VRE methodology, but this time with acknowledgment of the critical implications of how affect is embedded in the in situ uncertainty and the creativity of the researcher-participant relationship.

In their study of the use of VRE in bringing patients, health professionals, and researchers together to tackle infection prevention and control in hospitals, Wyer et al. (2017) adopt affect-as-method by acknowledging that affect works as a driver for both the researcher and the clinical team's impetus to learn, be moved, and to act through VRE. They take affect as a "point of departure, requiring that participants (clinicians, patients and researchers) harbor a capacity to affect and be affected" (Wyer et al., 2017, pp. 2-3). Collier (2013) similarly demonstrates affect-inaction in her study of experiences of safety in spaces of death and dying among palliative patients and their families. Through the use of VRE, Collier engaged with the "mess" of death and dying through becoming entangled in the spaces and relationships that she necessarily had to move through and with as a researcher in palliative care. She explains this as "... a turning toward the other in an attitude of openness and receptivity" and to "follow affective leads ... allowing a kind of bodily or somatic awareness to come to the fore" (p. 76).

Iedema and Carroll (2015), Wyer et al. (2017), and Collier (2013) detail how during VRE, it is not only participants but also researchers who become vulnerable as their own research practices and their interpretations of illness experiences are opened up for collaborative examination in reflexive sessions by researchers and participants alike. In this way, doing VRE through affect-as-method means that "engaged" or "entangled" observation necessarily becomes "vulnerable observation" (Behar, 1996). The researcher and participants become part of an "affective-analytical-political 
nexus" (Smith \& Kleinman, 2010, p. 172), which is transformed into "an ethical responsibility to the other, [that] emerges less from an intellectual or ethical decision and more from these fundamental emotional processes" (p. 174).

Affect-as-method cannot be about containment of the direction of the research, or the ensuing interpretations, meanings, and representations (Clough, 2009). This is a shift from the critical research paradigms that takes as its starting point a broader cause such as gender equity or patient advocacy, or particular social structure such as class, gender, race, or sexual orientation, reminiscent of the critical paradigm of the 1970s and 1980s (Davies, 2010). In agreement with Clough's (2009) assessment of affect in sociological method, Iedema and Carroll position affect as the impetus for what drives the interpretation and intervention. This is the key difference between what we refer to in this article as the "affect-as-method" mode of doing VRE, and broader research approaches. For example, although the issues that the VRE researcher engages with may be perfectly identifiable through frameworks such as "patient advocacy" or "improving safety and equity in health care," in affect-as-method, the knowledge construction and the VRE intervention are actually birthed from something that is tacitly or viscerally "felt" as a consequence of the shared intersubjective space of the field site. Importantly, it is this tacit or visceral impulse that is also the driver for VRE intervention, and is not something that can be predicted, predefined, or premeditated in advance of developing a socio-politicalaffective nexus in the field (Collier, 2013; Iedema \& Carroll, 2015). Thus, as it is conceptualized in this article, the affect-as-method approach to VRE deliberately attends to, and makes space for the researcher to "be moved" by the emergence of, and accrued affective potential generated by intersubjective encounters in the field. That is, affect is transmitted between researchers, participants, and the visual footage as a result of seeing, experiencing, and knowing alongside the health care professionals and patients in the study. Being with, and then establishing dynamic research relationships with health professionals or patients as participants to gain insider perspectives; being open to being moved to act without any certainty of outcome (Clough, 2009); and being attuned to, and working with the emergent affective complexity of clinical work are the chief components of the affect-as-method mode of doing VRE.

\section{Planned Obsolescence}

Similar to the researcher roles of clinalyst and affect-asmethod, in planned obsolescence, the VRE researcher aims to make a difference in the health care practice by building VRE into the clinical team as a lasting reflexive infrastructure. The premise of planned obsolescence is that VRE ultimately becomes a structural element of the health professional's teamwork, regardless of the presence of a researcher. In the planned obsolescence mode of VRE, the researcher becomes obsolete, and the locus of control and ownership of the project, including the roles and responsibilities for video ethnography and videoreflexivity, are taken on by the clinical team themselves. As a result, the key distinguishing feature between VRE as planned obsolescence and other modes of VRE is that it becomes a pro-active safety or quality improvement initiative that transforms VRE from an event associated with a visiting researcher into a "weekly/monthly meeting" that transforms health professionals into clinalysts.

Planned obsolescence requires a highly motivated team who wish to learn VRE, and take it on as part of an improvement infrastructure in the unit. As described by Mesman's (2015) work with VRE in neonatal intensive care, the researcher assists the health professionals to implement VRE in a way that ensures the methodology becomes their own. For planned obsolescence to be successful, structural resources are needed to secure methodological durability. A team of health professionals need to form a "video team" to come together at regular intervals to meet, evaluate, and organize VRE projects, and take the responsibility for videoing, facilitating the reflexivity sessions, and following up on practice optimization. Thus, within the video team, there are different roles. For example, two members of the team can act as "liaison officers" to communicate the outcomes to relevant stakeholders in and outside of the unit, while a chair of the video team can coordinate within the unit's team. The video team needs to master techniques of videoing and editing, and be able to prepare and chair the video-reflexivity sessions, including maintaining a constructive focus of analysis that translates the discussion into definitive learnings or practice-improvement measures. Communication infrastructures must be instituted within the video team to exchange information about the topics to be filmed, what is already filmed, by whom and when, what footage has been edited, and which topics are to be discussed during forthcoming reflexivity sessions. Then, learnings or practice change outcomes arising from the reflexivity sessions are communicated to the wider community of health professionals across the whole unit. With the assignment of roles and responsibilities within the video team, the methodology will become firmly situated in the particularities of the ward. Following this, as a result of the VRE experiences by the video team, VRE can be constantly refined to best fit the unit's needs and context, as the use of VRE requires a continuous "internal reengineering" (Carise, Cornely, \& Gurel, 2002) to make the project fit the structure and workflow of the ward. ${ }^{6}$

The main focus of planned obsolescence is on the training of a team of health care professionals to transform them into clinalysts. Iedema and Merrick (2009) 
successfully implemented planned obsolescence in their use of VRE with a variety of Australian health services sites, through the creation of the "HELiCS ${ }^{7}$ toolkit" which consists of an instructional booklet and DVD and website that packages VRE for health professionals to learn and then apply in clinical handovers (Iedema \& Merrick, 2009).

Yet once health care professionals are in full control of the choice of the topic, and the analytical process, is the title of "researcher" even appropriate? We argue it is. As a researcher engaging in VRE as planned obsolescence, we argue that this mode of VRE provides a passageway to "native experience" as the researcher becomes one of the video team members. This offers the researcher an excellent position from which to study, for example, issues of power, infrastructures of information, collaborative cultures, or communication processes in organizations (c.f. Mesman, 2015).

What is the difference between a health professionalclinalyst compared with a researcher-clinalyst? The researcher-clinalyst will typically inform the health professionals about the method, and in turn, they will provide advice about ways to make the best possible fit to the texture of the organization. In VRE as planned obsolescence, the researcher and the professionals are "primary collaborators" (Maienschein, 1993) and the researcher and the professionals can be considered as a "practiceimprovement collaborative" and members of the same team. Planned obsolescence is permeated by the ideology of empowerment (Pink, 2001, 2013) as it positions the participant at the center of knowledge production. Not in the role of co-researcher but as a professional who considers practice improvement as the core of his or her professional standards. VRE as planned obsolescence facilitates bottom-up improvements and supports collective decision making through real-time engagement and feedback. The video clips trigger discussions, questions, and a renewed awareness of how things can be done and why things are done in these ways. Video-reflexivity can be considered as a form of self-management as it is in and about one's own work environment. In this way, the expertise and experience of health care professionals, which have to date been marginalized in quality and safety programs (Iedema et al., 2013), are now used for tailor-made practice improvements. In the end, this is the ultimate goal of planned obsolescence.

\section{Discussion: The Epistemic Consequences of the Clinalyst, Affect-as-Method, and Planned Obsolescence}

The previous section reviews the evolution of VRE and has described three predominate styles of researcher engagement in doing VRE, including the division of tasks and responsibilities for researchers and health professionals, and the differing ways in which knowledge is produced. Each style of researcher engagement with VRE has specific implications for a researcher's relationship with participants, and for research-driven knowledge production and practice improvement. We believe, therefore, that it is important for VRE researchers to examine the epistemic assumptions embedded within the clinalyst, affect-as-method, and planned obsolescence as three ways of engaging with VRE. This is important to attend to, not because we advocate the hiding of anxieties and mess of engaging with the social world behind the surety offered by methods or by disciplines (Law, 2005). Instead, researchers face pragmatic concerns associated with twin goals of publishing quality academic work, while also meaningfully engaging with professionals and patients who use VRE to intervene in and optimize practices (Carroll \& Mesman, 2011). ${ }^{8}$

The VRE methodology demands researcher reflexivity. Simple questions, such as where to position yourself and the camera while videoing, when to record or put the camera away, and what to show back to participants during reflexive sessions, demand vast amounts of researcher attention (Carroll, 2009; Carroll \& Mesman, 2011). Yet researcher reflexivity extends beyond deploying the "method" of VRE. Doing reflexivity in qualitative research necessarily includes questioning assumptions of knowledge creation, including what counts as knowledge and how this knowledge is constructed in the research (Cannella, Salazar Pérez, \& Pasque, 2015; Carter \& Little, 2007; Denzin \& Lincoln, 2013; Lincoln \& Guba, 2013; Rakic \& Chambers, 2009). These epistemological concerns vary across methodologies as well as within them. For example, Rakic and Chambers (2009) argue that "subjectivity" and "reflexivity" need to play a central role in all video ethnographic projects as they consider end products of such projects as "a (re)construction, (re) creation and (re)presentation of a reality as it was perceived by its author" (p. 256). Importantly, they also have practical implications for conducting research (Crotty, 1998), for example, the type of researcher-participant relationships that researchers construct in the field, whose voice is heard and given credibility in analysis and data representation, how the researcher is represented in the process and his or her visibility, and how to assess research quality (Carter \& Little, 2007). In this way, epistemology shapes what and how methodology and methods are to be used, and as such, it is normative (Carter \& Little, 2007; Zuiderent-Jerak, Strating, Nieboer, \& Bal, 2009). More recent literature situates some ways of doing VRE as postqualitative. As a result of researchers becoming deeply involved in field relationships, practices, and politics, VRE may no longer represent "“what is' as 
knowledge but ... recount[s] what happened and what changed as a result of such research affecting what is" (Wyer et al., 2017, p. 9). Such a liminal position can create anxiety and ambiguity for some researchers, but liminality can also offer power and opportunity in qualitative research (Hart, Poole, Facey, \& Parsons, 2017). We now turn to examine this more closely in terms of how knowledge is produced in each of the three predominate ways researchers engage VRE.

In the clinalyst role, the researcher can be characterized by their collaborative approach in which the video footage acts as a medium through which new knowledge is created and articulated by health professionals and researchers alike. Here, the video-reflexivity sessions act as a "knowledge-lab" (Mesman, 2015) where familiar or everyday situations are reflected upon explicitly and collectively by the health professionals. The project-driven engagement of the clinalyst differs very much from the affect-as-method researcher in which the researchers' and participants' emergent affective knowing is a crucial resource to the deployment of VRE, particularly in identifying issues that may require intervention, and as a resource for driving the intervention itself (Iedema \& Carroll, 2015; Wyer et al., 2017). The specific issues of focus are determined as they arise in the field site rather than in advance of data collection. Thus, like the clinalyst, the researcher using VRE through the affect-asmethod lens offers to facilitate practice change, and offers herself as "outsider" to legitimate "artful contaminations" (Zuiderent-Jerak \& Jensen, 2007, p. 232) and "creative action" (Smith \& Kleinman, 2010, p. 180) in the guise of collaborative quality improvement and research interventions. Planned obsolescence shares the focus on practice optimization with the affect-as-method researcher and clinalyst. However, in the planned obsolescence mode, it is not the researcher who decides what areas of practice deserve attention. Instead, topics will be selected solely on the basis of the needs of the health professionals. Planned obsolescence does not exclude doing research. On the contrary, it positions the researcher as uniquely gaining insider's knowledge of particular aspects of the practice.

The boundary between being a researcher or a participant is blurred in each of the different ways of doing VRE. In the clinalyst role, VRE is a collaborative methodology where the distinction between analyst and health professional remains clear. The clinalyst aims to understand professionals' insider knowledge, and as such, the practices that are enacted by professionals are the subject of investigation. The researcher in both affect-as-method and planned obsolescence participates as a team member with a specific role in the broader practice of the health professionals, and, in turn, the health professionals also participate in the research. Therefore, we characterize the VRE researcher in affect-as-method and planned obsolescence as typical of researchers who adopt a participatory methodology through sharing and contributing to the affective and organizational space now occupied by both the researcher and health professionals. Thus, a clear boundary between the researcher and the participants as found in the clinalyst approach is diminished.

In addition to being used in academic research, VRE also aims to improve health care. It achieves this from within, by identifying already existing — but often overlooked or forgotten-competencies and resources of strength (Iedema et al., 2013; Mesman, 2011). Thus, VRE can be considered an act of "exnovation" (de Wilde, 2000; Mesman, 2008). Unlike innovation, exnovation does not intend to bring new elements into the practice but aims to explicate and use the already available resources. Exnovation offers a positive perspective on practices as it focuses on, and learns from the existent strengths of practice. How to identify these informaland at many times implicit—resources of strength? First, it requires an outsider's perspective to see it. Second, it requires insider's knowledge to recognize it. In other words, it requires a "situated distance" in which the familiar and the unfamiliar coincide. It is here that VRE enables health care professionals to recognize how their everyday routine activities are an extraordinary achievement that culminate in the delivery of complex, dynamic health care. VRE enables health care teams to exnovate their capacity and ingenuity. Put more simply, during these sessions, health professionals and patients reveal why they do things in a particular way and on what kind of assumptions these are based. Their reflexivity resembles the reflexivity one can find in academic articles, which intentionally describe the underlying epistemological assumptions regarding knowledge production. In the video-reflexivity sessions, health professionals and patients are reflexive and open about their underlying assumptions of what they produce in their everyday doing. Here, they rethink what they know, what they do, and importantly realize capabilities. For health professionals and patients, explicating one's own strength while watching footage about one's own work and care practices elicits a meta-discourse with which they can discuss practical and specific matters on a general level (Iedema et al., 2013). ${ }^{9}$ These kinds of reflections move health professional and patients' discussions and ensuing interventions away from one specific case to a more general and abstract level (Iedema et al., 2013). The clinalyst or affect-as-method researcher facilitates this meta-discourse during the video-reflexivity sessions, meanwhile in planned obsolescence the researcher teaches its significance and purpose during the implementation of the VRE methodology. 
VRE provides health care professionals and patients with a method to exnovate and thus explore, examine, and explicate their concerted, and at many times contingent, accomplishments. With these insights, they can, if needed, optimize their practice on the basis of their own expertise, experience, and suggestions. This bottom-up approach turns VRE into an instrument for empowerment as it provides health care professionals and patients the agency to optimize their work practices through their own insights.

\section{Conclusion}

VRE provides a space for collective data collection and analysis, facilitates bottom-up improvements, and supports collective decision making through real-time engagement and feedback. In this article, we have described three styles of doing VRE and their implications for the way knowledge is produced, what sort is produced, and how knowledge may be put to use by researchers, health professionals, administrators, patients, and families, or a unique combination of some or all. While doing this, the VRE researcher produces and juggles the politics of knowledge creation and critically assesses across the clinical and academic domains, walks a blurred path between analysis and intervention, and breaks down barriers between researchers and participants.

Our VRE experience has shown that briefly introducing the logic of knowledge that stands behind VRE is crucial in assisting funding bodies, gatekeepers, and participants in understanding and engaging with VRE, including judging VRE on its merits. It is important that stakeholders realize that collaborative and participatory research projects such as VRE involve standards of accomplishment, and that these often differ from objectivist standards like comprehension and completeness of knowledge ${ }^{10}$ (Carroll \& Mesman, 2011). VRE in the tradition of a "productive-reflexive" or "postqualitative" approach $^{11}$ aims not only for knowledge generation but also for practice change (Carroll \& Mesman, 2011; Wyer et al., 2017). By clearly explicating these underlying knowledge paradigms of VRE, those new to the use of video in qualitative research can access VRE as something useful, exciting, novel, or complementary to existing uses of video, and importantly, view VRE as methodologically rigorous in its own right. Moreover, transparent and consistent epistemological and methodological accounts remain important in the process of judging quality in academic peer review for obtaining research funding or publication (Carter \& Little, 2007).

The adaptions and evolutions of the VRE methodology over the past decade mean researchers can now choose from a greater variety of approaches as to how they will deploy VRE, engage participants, and participate in the construction of knowledge. With this article, we hope to provoke VRE researchers to consider, both in advance of entering the field and while embedded within its unique dynamics, their epistemological and methodological positioning as researchers, and the related implications and politics each have for their academic discipline, research goals, relationships with participants, and the emergent interventions arising from VRE use in the field site.

\section{Declaration of Conflicting Interests}

The author(s) declared no potential conflicts of interest with respect to the research, authorship, and/or publication of this article.

\section{Funding}

The author(s) received no financial support for the research, authorship, and/or publication of this article.

\section{Notes}

1. To date, video-reflexive ethnography (VRE) plays an increasing role in practice optimization such as improvements in patient safety in the intensive care unit (Carroll, 2009; Carroll, Iedema, \& Kerridge, 2008; Hor, Godbold, Collier, \& Iedema, 2013), the emergency department, spinal ward (Iedema \& Carroll, 2013; Long, Iedema, \& Lee, 2007), oncology teams (Lammer, 2009), radiology departments (Lammer, 2007) and pathology laboratories (Forsyth, 2006, 2009; Iedema, Forsyth, Georgiou, Braithwaite, \& Westbrook, 2007), palliative care (Collier, 2013), and surgical units (Wyer et al., 2015).

2. This notion is coined by the German philosopher Peter Sloterdijk (2013).

3. Ethnographic film is a topic of heated debates over its presumed illustrative aim or the position of the filmmaker (in the tradition of subjective relativism or objectifying realism). See, for example, Pink (2001), Rakic and Chambers (2009), and Ruby (2005) on this topic. A discussion on this issue falls outside the scope of this article. Within this genre, "community-collaborative film-making" as developed by Elder and Kamerling in the 1970s (Gubrium \& Harper, 2013) is closest to VRE, for they both share the principle of close collaboration with participants.

4. There are also other approaches that include active involvement of the participants in the knowledge production: community-based participatory research (CBPR), participatory research (PR) and participatory action research (PAR), and collaborative ethnography, to name a few, under which we do not situate the hospital-based VRE methodology. These approaches should not be considered as pure typologies (Stoecker, 1999).

5. For this reason, we will consider the clinalyst role as the founding or standard approach to hospital-based VRE, and therefore, here, we dedicate a considerable space to analyzing the clinalyst role before building upon it with the two subsequent VRE researcher roles that we offer. 
6. On several wards in the Maastricht University Medical Center in the Netherlands, health care professionals have turned into clinalysts and use the methodology of videoreflexivity as a permanent feature of their ward and have become independent from the presence of an outsider/ researcher.

7. HELiCS is an acronym for "Handover: Enabling Learning in Communication (for) Safety."

8. We are aware that this tension is not unique for VRE but also experienced in other participatory research projects (Gubrium \& Harper, 2009).

9. We are aware that neither visual data nor meta-discourse will eradicate existing power relations (Mannay, 2013).

10. Often stakeholders are more familiar with the objectivist use of video in health care research, such as a mounted camera that will provide footage that will be content analyzed for the total duration of resuscitations in emergency departments, for example, or the number of entrances to an operating theater while a patient is undergoing surgery. In this "objectivist" approach, the knowledge production, the verification of observations, and the reliability of interpretations are center-staged.

11. From a methodological perspective, this approach can be labeled as a subjectivist relativist position (Rakic \& Chambers, 2009).

\section{References}

Adomat, R., \& Hicks, C. (2003). Measuring nursing workload in intensive care: An observational study using closed circuit video cameras. Journal of Advanced Nursing, 42, 402-412. doi:10.1046/j.1365-2648.2003.02632.x

Behar, R. (1996). The vulnerable observer. Boston: Beacon Press.

Bloustein, G. (2003). Introduction: Envisioning ethnographyExploring the meaning of the visual in research. Social Analysis, 47(3), 1-7.

Cannella, G., Salazar Pérez, M., \& Pasque, P. (2015). Critical qualitative inquiry: Foundations and futures. Walnut Creek, CA: Left Coast Press.

Carise, D., Cornely, W., \& Gurel, O. (2002). A successful researcher-practitioner collaboration in substance abuse treatment. Journal of Substance Abuse Treatment, 23, $157-162$.

Carroll, K. (2009). Insider, outsider, alongsider: Examining reflexivity in hospital-based video research. International Journal of Multiple Research Approaches, 3, 246-263.

Carroll, K., Iedema, R., \& Kerridge, R. (2008). Reshaping ICU ward round practices using video-reflexive ethnography. Qualitative Health Research, 18, 380-390. doi:10.1177/1049732307313430

Carroll, K., \& Mesman, J. (2011). Ethnographic context meets ethnographic biography: A challenge for the mores of doing fieldwork. International Journal of Multiple Research Approaches, 5(5), 246-263.

Carter, S., \& Little, M. (2007). Justifying knowledge, justifying method, taking action: Epistemologies, methodologies, and methods in qualitative research. Qualitative Health Research, 17, 1316-1328. doi:10.1177/1049732307306927
Cheshire, L. (2016, June). Thinking big (and critically) about qualitative research: Trends, visions and challenges for the future of qualitative social science. ACSPRI Annual Conference. Retrieved from http://studyres.com/ doc/3248559/thinking-big-and-critically-about-qualitativeresearch-

Clough, P. (2009). The New Empiricism: Affect and sociological method. European Journal of Social Theory, 12, 43-61. doi: $10.1177 / 1368431008099643$

Collier, A. (2013). Deleuzians of patient safety: A videoreflexive ethnography of end-of-life care (Doctoral thesis). University of Technology, Sydney.

Crotty, M. (1998). The foundations of social research: Meaning and perspective in the research process. Sydney: Allen \& Unwin.

Davies, J. (2010). Introduction. In J. Davies \& D. Spencer (Eds.), Emotions in the field: The anthropology and psychology of fieldwork experience (pp. 1-34). Stanford, CA: Stanford University Press.

Denzin, N., \& Lincoln, Y. S. (2013). The landscape of qualitative research. London: Sage.

de Wilde, R. (2000, December 1-3). Innovating innovation: A contribution to the philosophy of the future. Paper at the Policy Agendas for Sustainable Technology Innovation Conference, London.

Forsyth, R. (2006). Tricky technology, troubled tribes: A video ethnographic study of the impact of information technology on health care professionals' practices and relationships (Doctoral thesis). University of New South Wales, Sydney.

Forsyth, R. (2009). Distance versus dialogue: Modes of engagement of two professional groups participating in a hospitalbased video ethnographic study. International Journal of Multiple Research Approaches, 3, 276-289.

Gubrium, A., \& Harper, K. (2009). Visualizing change: Participatory digital technologies in research and action. Practicing Anthropology, 31(4), 2-4.

Gubrium, A., \& Harper, K. (2013). Participatory visual and digital methods. Walnut Creek, CA: Left Coast Press.

Guerlain, S., Turrentine, B., Adams, R., \& Calland, J. F. (2004). Using video data for the analysis and training of medical personnel. Cognition, Technology \& Work, 6, 131-138.

Harrison, B. (2002). Seeing health and illness worlds - Using visual methodologies in a sociology of health and illness: A methodological review. Sociology of Health \& Illness, 24, 856-872. doi:10.1111/1467-9566.00322/abstract

Hart, C., Poole, J., Facey, M., \& Parsons, J. (2017). Holding firm: Power, push-back, and opportunities in navigating the liminal space of critical qualitative health research. Qualitative Health Research, 27, 1765-1774. doi:10.1177/1049732317715631

Heath, C., Luff, P., \& Svensson, M. S. (2007). Video and qualitative research: Analysing medical practice and interaction. Medical Education, 41, 109-116.

Hor, S., Godbold, N., Collier, A., \& Iedema, R. (2013). Finding the patient in patient safety. Health, 17, 567-583. doi: $10.1177 / 1363459312472082$

Hynes, M. (2013). Reconceptualizing resistance: Sociology and the affective dimensions of resistance. The British Journal of Sociology, 64, 559-577.

Hynes, M., \& Sharpe, S. (2015). Affect. Angelaki, 20, 115-129. 
Iedema, R., \& Carroll, K. (2010). Discourse research that intervenes in the quality and safety of care practices. Discourse \& Communication, 4, 68-86.

Iedema, R., \& Carroll, K. (2011). The "clinalyst": Institutionalizing reflexive space to realize safety and flexible systematization in health care. Journal of Organizational Change Management, 24, 175-190. doi:1 $0.1108 / 09534811111119753$ ?fullSc $=1$

Iedema, R., \& Carroll, K. (2013). Intervening in health care communication using discourse analysis. In J. Flowerdew (Ed.), Discourse(s) and context(s) (pp. 185-204). London: Continuum.

Iedema, R., \& Carroll, K. (2015). Research as affect-sphere: Towards spherogenics. Emotion Review, 7, 67-72. doi: $10.1177 / 1754073914544477$

Iedema, R., Forsyth, R., Georgiou, A., Braithwaite, J., \& Westbrook, J. (2007). Video research in health: Visibilizing the normative and affective complexities of computerizing care. Qualitative Research Journal, 6, 15-30.

Iedema, R., Long, D., Forsyth, R., \& Lee, B. (2006). Visibilising clinical work: Video ethnography in the contemporary hospital. Health Sociology Review, 15, 156-168.

Iedema, R., \& Merrick, E. (2009). HELiCS as a tool for ongoing observation, monitoring and evaluation of clinical handover-Public report on pilot study. Retrieved from https:/www.safetyandquality.gov.au/wp-content/ uploads/2012/01/HELiCS-PubRep.pdf

Iedema, R., Merrick, E., Rajbhandari, D., Gardo, A., Stirling, A., \& Herkes, R. (2009). Viewing the taken-for-granted from under a different aspect: A video-based method in pursuit of patient safety. International Journal of Multiple Research Approaches, 3, 290-301.

Iedema, R., Mesman, J., \& Carroll, K. (2013). Visualising health care practice improvement: Innovation from within. London: Radcliffe Publishing.

Jørgensen, A. M. (2007). Filmmaking as ethnographic dialogues: Rouch's family of "scoundrels" in Niger. Visual Anthropology, 20, 57-73.

Kindon, S. (2003). Participatory video in geographic research: A feminist practice of looking? Area, 35, 142-153.

Lammer, C. (2007). Bodywork: Social somatic interventions in the operating theatres of invasive radiology. In S. Pink (Ed.), Visual interventions-applied visual anthropology (1st ed., Vol. 4, pp. 91-118). Oxford, UK: Berghahn Books.

Lammer, C. (2009). Translating experience: The creation of videos of physicians and patients in the environment of an Austrian university hospital. International Journal of Multiple Research Approaches, 3, 264-275.

Law, J. (2005). After method: Mess in social science research. London: Routledge.

Lincoln, Y., \& Guba, E. (2013). The constructivist credo. Walnut Creek, CA: Left Coast Press.

Long, D., Iedema, R., \& Lee, B. (2007). Corridor conversations: Clinical communication in casual spaces. In R. Iedema (Ed.), Communicating hospital work: Tracing complexities in contemporary health care (pp. 182-200). Basingstoke, UK: Palgrave Macmillan.

Maienschein, J. (1993). Why collaborate. Journal of History of Biology, 26, 167-183.
Mannay, D. (2013). "Who put that in there . . why why why?" Power games and participatory techniques of data production. Visual Studies, 28, 136-146.

McLeod, H. M. (2017). Respect and shared decision-making in the clinical encounter: A video-reflexive ethnography (Doctoral dissertation). University of Minnesota, Minneapolis.

Mesman, J. (2008). Uncertainty in medical innovation: experienced pioneers in neonatal intensive care. Hampshire: Palgrave MacMillan.

Mesman, J. (2011). Resources of strength: An exnovation of hidden competences to preserve patient safety. In E. Rowley \& J. Waring (Eds.), A socio-cultural perspective on patient safety (pp. 71-91). Farnham, UK: Ashgate.

Mesman, J. (2015). Boundary-spanning engagements on a neonatal ward: Reflections on a collaborative entanglement between clinicians and a researcher. In B. Penders, N. Vermeulen, \& J. Parker (Eds.), Collaboration across health research and medical care: Healthy collaboration (pp. 171-194). Surry, UK: Ashgate.

Pinch, T., Collins, H., \& Carbone, L. (1996). Inside knowledge: Second order measures of skill. The Sociological Review, 44, 163-186.

Pink, S. (2001). More visualising, more methodologies: On video, reflexivity and qualitative research. The Sociological Review, 49, 586-599.

Pink, S. (2011). Images, senses and applications: Engaging visual anthropology. Visual Anthropology, 24, 437-454. doi:10.1080/08949468.2011.604611

Pink, S. (2013). Doing visual ethnography. London: Sage.

Rakic, T., \& Chambers, D. (2009). Researcher with a movie camera: Visual ethnography in the field. Current Issues in Tourism, 12, 255-270. doi:10.1080/13683500802401972

Ruby, J. (2005). The last 25 years of visual anthropology-A critical review. Visual Studies, 20, 159-170. doi:10.1080/14725860500244027

Siassakos, D., Bristowe, K., Draycott, T., Angouri, J., Hambly, H., Winter, C., . . . Rox, R. (2011). Clinical efficiency in a simulated emergency and relationship to team behaviors: A multisite cross-sectional study. BJOG: An International Journal of Obstetrics \& Gynaecology, 118, 596-607.

Sloterdijk, P. (2013). You must change your life. Cambridge, UK: Polity Press.

Smith, L., \& Kleinman, A. (2010). Emotional engagements: Acknowledgement, advocacy and direct action. In J. Davies \& D. Spencer (Eds.), Emotions in the field: The psychology and anthropology of fieldwork experience (pp. 171-187). Palo Alto, CA: Stanford University Press.

Stoecker, R. (1999). Are academics irrelevant? American Behavioral Scientist, 42, 840-854.

Thrift, N. (2004). Intensities of feeling: Towards a spatial politics of affect. Geografiska Annaler, 86B, 57-78.

Williams, J., Jones, N., Richardson, F., Jones, C., \& Richmond, P. (1996). The nursing triage process: A video review and a proposed audit tool. Journal of Accident \& Emergency Medicine, 13, 398-399.

Willis, E. (2010). The problem of time in ethnographic health care research. Qualitative Health Research, 20, 556-564. doi:10.1177/1049732310361243 
Wyer, M., Iedema, R., Hor, S., Jorm, C., Hooker, C., \& Gilbert, G. (2017). Patient involvement can affect clinicians' perspectives and practices of infection prevention and control: A "post-qualitative" study using video-reflexive ethnography. International Journal of Qualitative Methods, 16, 1-10. doi:10.1177/1609406917690171

Wyer, M., Jackson, D., Iedema, R., Hor, S., Gilbert, L., Jorm, C., \& Carroll, K. (2015). Involving patients in understanding hospital infection control using visual methods. Journal of Clinical Nursing, 24, 1718-1729.

Xiao, Y., \& Mackenzie, C. (2004). Introduction to the special issue on video-based research in high risk settings: Methodology and experience. Cognition, Technology \& Work, 6, 127-130.

Xiao, Y., Seagull, F. J., Mackenzie, C., \& Klein, K. (2004). Adaptive leadership in trauma resuscitation teams: A grounded theory approach to video analysis. Cognition, Technology \& Work, 6, 158-164. doi:10.1007/s10111-0040157-z

Zuiderent-Jerak, T., \& Jensen, C. B. (2007). Editorial introduction: Unpacking "intervention" in Science and
Technology Studies. Science as Culture, 16, 227-235. doi:10.1080/09505430701568552

Zuiderent-Jerak, T., Strating, M., Nieboer, A., \& Bal, R. (2009). Sociological refigurations of patient safety; ontologies of improvement and "acting with" quality collaboratives in healthcare. Social Science \& Medicine, 69, 1713-1721.

\section{Author Biographies}

Katherine Carroll is a research fellow in the School of Sociology at the Australian National University. Aside from theorising and conducting video reflexive ethnography, her research interests include a sociology of reproductive tissue banking and donation, focusing on breastmilk and oocytes.

Jessica Mesman is an associate professor in the Department of Technology and Society Studies at Maastricht University, The Netherlands. Her research interest include the anthropology of knowledge and the method of video-reflexivity in critical care medicine, particularly the exnovation of informal and unarticulated dimensions of establishing and preserving safety in health care practices. 